\title{
Editor's Welcome to the Inaugural Issue of the Journal of Prison Education and Reentry
}

\author{
ARVE ASBJØRNSEN \\ Lead Editor \\ University of Bergen, Norway
}

Dear reader:

It is with great pride we present this first issue of Journal of Prison Education and Reentry. This marks the end of an extensive period of preparations, following the recognition of a need for an independent, open access, and widely available platform for exchange of research and brilliant ideas for best practice in prison education and reentry. We greet the birth of the journal with expectations of a long and prosperous life.

It is also with pride that we present this first issue of the journal on the anniversary of the Council of Europe's adoption of the recommendations concerning prison education. This is our ultimate support for the International Day of Prison Education.

Much of what happens in prison is out of the public's view. Global social and economic events - such as massive refugee movements and the collapse of financial markets - have profound impacts on the world inside prisons. It is hard to sort out the effects these have on prison education and reentry policies and programs. Frequently, educators in prisons work in challenging situations, often having few colleagues with whom to share their experiences and who can offer support. The call for proof beyond doubt that "it works" is louder than ever, and the search for "evidence based practice" is permeating prison education. Therefore, it is necessary for researchers and practitioners to share their knowledge and experience, and to collaborate in the quest for establishing the criteria that will define "best practice". However, it is also necessary at times to critique the standards movement itself, especially when the complexities of the systems we work within and research have conflicting purposes and missions. We sincerely hope JPER can yield a small, but significant, contribution to this work and dialogue.

JPER accepts different categories of submissions. For the Research Section, we accept submissions of original research, and all submissions are subjected to a rigorous peer review process before a final decision of publication is met. For the Practitioner Section, the submissions are assessed by the Section Editor and her assistant, in addition to the Lead Editor. For the Features Section, all submissions are assessed by the Lead Editor.
In this first issue of JPER, we present four original research contributions, in addition to some very important and readable discussions of practice in prison education. The first research article, written by Kariane Westrheim and Terje Manger, presents results from an interview study among prisoners originating in Iraq, but incarcerated in Norway. Analyses of educational needs and approval of qualifications among prisoners who have been educated in a different educational system is a great challenge. The paper offers insights into the education of Iraqi prisoners in Norway, but also presents a methodological approach to assessment of educational needs in atypical subsamples of learners. The second paper, written by Cormac Behan, similarly presents results of an interview study among prisoners, but his study applies a more open-ended approach, and starts by examining the motives for taking up education and continues to explore the functions of education from the perspectives of prisoners in Ireland. His conclusions are very much worth considering: prison education needs to distinguish itself from rehabilitation programmes and stand on the integrity of its profession, based on principles of pedagogy, rather than be lured into the evaluative and correctional milieu of modern penalty. We are also proud to present the first part of a two-part paper by Randall Wright, where he is using normalization theory to discuss various forces that shape prison-student identities. 'Performative spaces' and 'identity closure' are used to explore the identity work that occurs in schools and elsewhere in prisons, and how this helps to explain how education can facilitate reentry. Finally, Susan Hopkins invites a discussion on the teaching of incarcerated tertiary students in the digital age and some of the dilemmas of higher education in prisons.

For the Practitioners Section, we have received a substantial number of submissions that are worth your time to read.

We have themed the first issue around several papers describing aspects of establishing college programs in prisons along with an introduction by our Editor for practitioners' papers, Anne Costelloe. We have "Fluorescent Glow" by Micol Hutchinson, who tells her story of teaching English as a second language in a

Correspondence: Arve Asbjørnsen, Email: arve.asbjornsen@psybp.uib.no 
city jail. We bring you Part 1 of "Otisville Diaries" by Baz Dreisinger and her colleagues, in "Prisons, Pipelines, and Pedagogy". Part 2 will be published later this year. In addition, we bring you the insiders' perspectives on participation in a collaborative college program at Richmond City Jail ("Sanctuary in the Richmond City Jail" by Croft, Flynn, Irving and Yang). Finally we have also included in this issue a similar story, but formed by the education of college teachers to work in prisons and with the incarcerated students ("Waking up in prison: Critical discussions between typical college students and their incarcerated peers" by Tabitha Dell'Angelo).

Hutchinson's article also includes a link to a video presentation of a particular student of hers that you probably will find of interest. Presentations like this indicate the wonderful possibilities of online publishing: attachment of a wealth of additional material, and also the possibility to link to all the vast information available on the internet. However, with great opportunities, there is also great responsibility. It is a huge challenge to also make sure that what is shared is open for sharing. Perhaps this publication will inspire others to also think "outside the box" when conveying stories of good practice?

The journal is published as open access, which means everyone with access to the internet is able to read and download all content of the journal. It can also be shared without limitations as long as the source is clearly stated. Everything is published according to the Creative Commons 4.0, share alike, which includes the right to use and reuse the material for non-commercial use. The ownership is not taken over by JPER, but remains with the author, which also grants the author all rights to use of the publications, including posting in repositories, sharing on the internet, or printing as many copies as he or she likes to share with colleagues, friends or family, or to also use in an anthology. We publish JPER using the Open Journal System (OJS) developed by the Public Knowledge Project (PKP). Both CC and OJS are developed in the same spirit as has motivated this journal: free access to knowledge, independent of location, status, or economy. The archives of JPER are generously hosted by the University
Library of the University of Bergen through their repository, the Bergen Open Research Archives (BORA), which will assure the availability of all published material for the future.

We hope you find something inspiring, something challenging, and maybe also something so annoying that you hit your keyboard and write us. You will also find us on Facebook (https://www.facebook.com/\#!/ JournalofPrisonEducationandReentry) and on Twitter (@JPERatBORA), additional and excellent places to share thoughts and comments on the content of the journal.

To conclude this column, I would like to thank my friends and colleagues, Anne Costelloe and Bill Muth, who accepted the challenges of serving as section editors, for their extensive work and energy in getting this journal published. We have received fantastic support from the University Library of the University of Bergen, in particular from Tarje Lavik and Ingrid Cutler, who are doing a wonderful job with the Bergen Open Research Archives where this journal has its home. Also, I am immensely grateful to Virginia Commonwealth University for generously allocating doctoral student positions to the Journal. In particular, I wish to recognize Laura Gogia and Ginger Walker for their efforts in keeping the work on track and taking care of all the administrative challenges and technicalities of setting up the journal, and to Michael Scott for doing a fantastic job with the adaptation of the platform and taking care of templates and lay-out issues. We are grateful for all discussion within the extended Executive Board - Thom Gehring, Carolyn Eggleston, Terje Manger and Cormac Behan--who have offered wonderful insightful and innovative discussions through the whole work process. The quality standards required for research publication could not have been assured without the hard work of our Editorial Review Board members (for a list of reviewer names, see https:// jper.uib.no/jper/about/editorialTeam). Finally, a warm thank you to the president of the EPEA, both the present president, Lena Broo, and the former president Anita Wilson, for giving us opportunities to meet and discuss the journal and other matters of importance during the EPEA conferences. 